DOI: 10.47456/krkr.v2i5.32571

\title{
Reflexões das ações do PIBID no processo formativo de docentes na Educação do Campo
}

\author{
Reflections of PIBID actions in the training process of teachers in Rural
} Education

Denise da Silva

Aniara Ribeiro Machado Algacir José Rigon

\begin{abstract}
Resumo: Neste trabalho apresentamos reflexões a partir dos relatos e observações acumuladas a partir das vivências dos acadêmicos e acadêmicas do Curso de Educação do Campo - Licenciatura com ênfase em Ciências da Natureza, da Universidade Federal do Pampa, no Programa Institucional de Bolsas de Iniciação à Docência (PIBID) no período de 2018 a 2020. Neste processo participaram 24 bolsistas distribuídos em três escolas no campo, duas de Dom Pedrito e uma de Sant'Ana do Livramento, atendendo uma média de 300 estudantes da Educação Básica. A abordagem foi de cunho qualitativo na perspectiva da "observação em campo" com anotação de informações sobre a realidade. O trabalho desenvolvido partiu das demandas das escolas, sendo que estas foram identificadas a partir da inserção dos estudantes no cotidiano e a partir do diálogo com docentes das diferentes áreas do conhecimento e comunidades. Isso culminou em diferentes propostas e ações educativas, dentre elas destacamos as seguintes: i) horta escolar e plantas alimentícias não convencionais; ii) agrofloresta; iii) composteira e minhocário iv) revitalização da área dos pomares. Como resultado percebemos que: a) é possível ensinar ciências tendo como ponto de partida a prática social da comunidade escolar, uma vez que toda a vida humana está cercada pelas Ciências da Natureza (Biologia, Física e Química); b) que é possível superar o cotidiano precarizado e irrefletido com amparo na ciência; c) aprendizagem por meio do "ensino lúdico", jogos pedagógicos e atividades experimentais. Frente a esses elementos o PIBID tem sido fundamental para qualificar o processo formativo dos discentes, formadores e supervisores.
\end{abstract}

Palavras-Chave: PIBID, Educação do Campo, Formação de Professores

Abstract: In this work we present reflections from the reports and observations accumulated from the experiences of the students of the Course of Education of the Field - Degree with emphasis in Sciences of the Nature, of the Federal University of Pampa, in the Institutional Program of Scholarships of Initiation to Teaching (PIBID) in the period from 2018 to 2020 . In this process, 24 fellows participated in three schools in the countryside, two in Dom Pedrito and one in Sant'Ana do Livramento, serving an average of 300 Basic Education students. The approach was qualitative in the perspective of "field observation" with annotation of information about reality. The work developed came from the demands of the schools, and these were identified from the insertion of students in daily life and from the dialogue with teachers from different areas of knowledge and communities. This culminated in different educational proposals and actions, among which we highlight the following: i) school garden and unconventional food plants; ii) agroforestry; iii) composter and earthworm iv) revitalization of the orchard area. As a result, we realize that: a) it is possible to teach sciences taking as a starting point the social practice of the school community, since all human life is surrounded by the Sciences of Nature (Biology, Physics and Chemistry); b) that it is possible to overcome the precarious and thoughtless daily life with support 
in science; c) learning through "playful teaching", educational games and experimental activities. Faced with these elements, PIBID has been instrumental in qualifying the training process of students, trainers and supervisors.

Keywords: PIBID, Rural Education, Teacher Education

\section{Introdução}

O Curso de Educação do Campo - Licenciatura (LeCampo), com ênfase em Ciências da Natureza, da Universidade Federal do Pampa - UNIPAMPA, Campus Dom Pedrito RS, participou pela primeira vez de um edital CAPES para o Programa Institucional de Iniciação à Docência (PIBID) no ano de 2018. O Curso foi contemplado com vinte e quatro (24) cotas de bolsas de Iniciação a docência, três (3) cotas de bolsas de Supervisor da Educação Básica, e seis (6) voluntários, sob a coordenação de três professores do Curso. Neste cenário tivemos a participação de três escolas que estão situadas no campo, sendo duas em Dom Pedrito-RS, as quais são de Ensino Fundamental (Anna Riet Pinto e Risoleta Quadros) e uma escola de Ensino Médio (Antônio Conselheiro), em Sant'Ana do Livramento-RS.

O PIBID é uma política pública que busca qualificar a formação dos licenciandos e licenciandas por meio de sua inserção nas escolas desde o primeiro ano de sua formação. Nesse sentido, os objetivos iniciais foram na perspectiva de problematizar, a partir de discussões oriundas da área da Educação do Campo, a organização curricular por área do conhecimento em escolas do campo e escolas urbanas que abrangem o Tempo Comunidade da LeCampo na região da campanha; ainda, abordar estratégias de organização do trabalho docente nas escolas do campo de modo a promover espaços de reflexão e vivência escolares, que possibilitassem, aos estudantes, experienciarem diferentes aspectos da realidade social e educacional em escolas do campo ou escolas urbanas que recebem estudantes do campo. Não menos importante, a busca por qualificar o debate sobre o lugar dos cursos de licenciaturas no fortalecimento do ensino superior público e no processo de ensino e aprendizagem de conteúdos científicos da área das Ciências da Natureza.

Conforme a CAPES, o PIBID 
O Pibid é uma ação da Política Nacional de Formação de Professores do Ministério da Educação (MEC) que visa proporcionar aos discentes na primeira metade do curso de licenciatura uma aproximação prática com o cotidiano das escolas públicas de educação básica e com o contexto em que elas estão inseridas. O programa concede bolsas a alunos de licenciatura participantes de projetos de iniciação à docência desenvolvidos por instituições de educação superior (IES) em parceria com as redes de ensino. Os projetos devem promover a iniciação do licenciando no ambiente escolar ainda na primeira metade do curso, visando estimular, desde o início de sua formação, a observação e a reflexão sobre a prática profissional no cotidiano das escolas públicas de educação básica. Os discentes serão acompanhados por um professor da escola e por um docente de uma das instituições de educação superior participantes do programa. (BRASIL, 2020, p. $s / p)$.

Apesar de ser um Programa de cunho Nacional, cada instituição participa das chamadas (Editais) periódicas com um Projeto Institucional que é, ou não, selecionado conforme os respectivos critérios divulgados pela CAPES. Institucionalmente cada projeto é constituído por subprojetos que são identificados com cada uma das licenciaturas, ou por um subprojeto composto por duas ou três licenciaturas com áreas afins. No nosso caso, a Unipampa participou de com um Projeto composto por quatro subprojetos, sendo um desses específico da Educação do Campo que, uma vez selecionados, foram concedidas bolsas e deu-se início ao processo.

Criaram-se grupos de estudos. Considerando que os acadêmicos estão no início da licenciatura, optou-se por mostrar-lhes, na forma de seminários, alguns documentos importantes, como o Plano Nacional de Educação (PNE) e a Base Nacional Comum Curricular (BNCC), a qual vem sendo estudada/discutida para implementação nas escolas. Concomitantemente realizaram-se imersões, a partir de observações, reconhecimento da comunidade escolar, a qual respondeu a questionários e entrevistas. Houve o cuidado para que sempre houvesse um "tempo" de estudos e sistematizações, para tal, e reuniões semanais com todos. Nestes espaços era possível avaliar as ações, bem como estudar sobre outras possibilidades pedagógicas.

Frente ao exposto, a abordagem foi de cunho qualitativo na perspectiva da "observação em campo" com anotação de informações sobre a realidade 
(GATTI; ANDRÉ, 2010). Nesse contexto os observadores estão inseridos na realidade, no cotidiano, e participam tanto do planejamento quanto da execução das atividades. $O$ registro das informações foi feito nos Cadernos de Alternância ${ }^{1}$ por parte dos bolsistas, de modo que a releitura dos mesmos viabiliza a recuperação da memória dos fatos ocorridos, bem como a identificação dos problemas, das discussões realizadas, das propostas e ações educativas. Tal procedimento viabilizou perceber as motivações e comportamentos dos participantes envolvidos que seriam inacessíveis em outro formato.

Para tanto apresentamos nesse artigo algumas dessas reflexões a partir dos relatos e observações acumuladas com base nas vivências dos acadêmicos e acadêmicas do Curso de Educação do Campo - Licenciatura com ênfase em Ciências da Natureza, da Universidade Federal do Pampa, no PIBID no período de setembro de 2018 a janeiro de 2020.

\section{Contexto das Escolas}

O cenário encontrado nas escolas esteve atrelado ao contexto do campo, isto é, escolas nucleadas e situadas distantes das residências dos educandos de modo que esses acessam a escola por meio do transporte público. Isso coloca algumas dificuldades extras ao processo pedagógico, pois observamos que nas três escolas, temos casos de alguns alunos que passam mais de três horas diárias em um meio de transporte. A rotina deixa os alunos cansados, às vezes exaustos, provocando desinteresse nas aulas ou nas atividades que exijam uma demanda maior de concentração. Isso, sem contar, que, em dias de chuva, as estradas ficam inacessíveis e as aulas acabam

\footnotetext{
${ }^{1}$ Os acadêmicos do Curso de Educação do Campo- Licenciatura utilizam como instrumento de escrita e registro dos tempos (Universidade e Comunidade) o Caderno de Alternância. O referido caderno "traz informações sobre o contexto socioambiental local capaz de revelar o extraordinário na banalidade aparente do cotidiano, expressando também uma dimensão da expressão pessoal onde estão presentes sentimentos, reflexões e pensamento". (CERQUEIRA; SANTOS, 2012, p. 2).
} 
suspensas em vista de não ocorrer o transporte dos alunos. Para recuperar as aulas as escolas fazem a "dobradinha", isto é, há dias em que os turnos das aulas são ampliados, por exemplo, sendo as aulas de manhã, há continuidade de aulas a tarde. A realidade de acesso a escola, vivida pelos estudantes, se estende a vários professores, pois alguns residem na cidade e se deslocam às escolas.

Nas escolas de Dom Pedrito, temos uma professora com formação específica na área de Educação do Campo - Ciências da Natureza, que atende as demandas das séries finais do Ensino Fundamental. Na outra escola contamos com a supervisão de um professor com formação inicial em Ciências do Ensino Fundamental, o qual também atende as demandas da área de Ciências da Natureza nas séries finais do Ensino Fundamental. Na escola de Sant'Ana do Livramento tivemos num primeiro momento a participação de uma supervisora com formação em Ciências Biológicas, a qual traz em sua trajetória acadêmica a participação em projetos de extensão e pesquisa, e também no PIBID como bolsista. Num segundo momento contribuiu como supervisor um professor com formação em História que desenvolve atividades formativas com foco na Agroecologia.

Com relação a responsabilidade jurídica, duas escolas participantes são de responsabilidade do Estado do RS, e uma do município de Dom Pedrito. Nas escolas do Estado se vive o movimento de implementação da BNCC, em que gestores e professores têm recebido formação para as mudanças na organização formativa das escolas e isso estendeu-se as(os) Pibidianas(os) no processo.

Com relação a infraestrutura, podemos dizer que, nas escolas estaduais, tínhamos a disposição uma biblioteca, sala de informática e uma sala laboratório, muitas vezes utilizado para outros fins. Na escola municipal, não tínhamos esses espaços e as atividades muitas vezes foram realizadas no refeitório, o qual era o maior espaço da instituição. 


\section{Dinâmica do Curso da LeCampo}

O curso de Educação do Campo compõe o quadro de licenciaturas da UNIPAMPA, enquanto universidade multicampi. A LeCampo está organizada no regime de alternância, sendo que ocorrerá, a cada semestre um Tempo Universidade (TU) e um Tempo comunidade (TC). "No semestre verão teremos o TU em janeiro e fevereiro e TC de março a junho, no semestre inverno o TU ocorre em julho e o TC de agosto a novembro (PPC, 2016, p. 44)". Sendo organizado de forma diversa aos cursos tradicionais, implicando 0 deslocamento dos docentes até a comunidade dos discentes no TC, isso pode representar alguma dificuldade no aspecto econômico. Por outro lado, tal condição permite que a Unipampa se capilarize nos diferentes espaços de abrangência através de seus Campi e cidades limítrofes da região. Assim, realiza-se uma das metas específicas da Instituição de Ensino Superior (IES) que é a formação de sujeitos inseridos e comprometidos com o desenvolvimento regional.

Nesta região, a realidade do campo, em especial, é de parcos investimentos públicos e de grandes concentrações de terra e renda, o que inviabilizou ao longo dos anos a ocupação e adensamento populacional do campo (CHELOTTI; PESSÔA, 2007). Isso afeta, ainda, os índices educacionais e o próprio investimento na educação escolar dos filhos dos camponeses, uma vez que com baixa densidade populacional as escolas também possuem um menor número de educandos e, em vista da questão econômica, os governos têm se negado a fazer investimentos de qualquer ordem (infraestrutura, transporte, formação de professores etc.).

Nesta região o alicerce da atividade econômica recai sobre a monocultura do arroz e da soja, ou ainda, da pecuária, não aparecendo muitas outras alternativas que viabilizem um desenvolvimento diferente da região (SANTOS; DAVID, 2011). A produção e atividades dessa natureza, que no mais das vezes é voltada para a produção de commodities, perpetua um legado de destruição da natureza, em específico do Bioma Pampa. Tal situação provoca certa construção cultural e a criação de uma identidade do território que é precário em termos de outras alternativas de produção de 
alimentos. Muito embora apareçam alternativas como a vitivinicultura, a região tem potencial para muitas outras culturas e formas de produção, o que corrobora a tese de que a educação por meio da formação de professores, em especial os que atuam da educação do campo, podem fazer uma diferença enorme.

Em vista disso, a justificativa para criação do curso da Lecampo recai, exatamente, na possibilidade de mudança do processo produtivo agrícola que atualmente é realizado de modo intenso e exploratório dos recursos naturais.

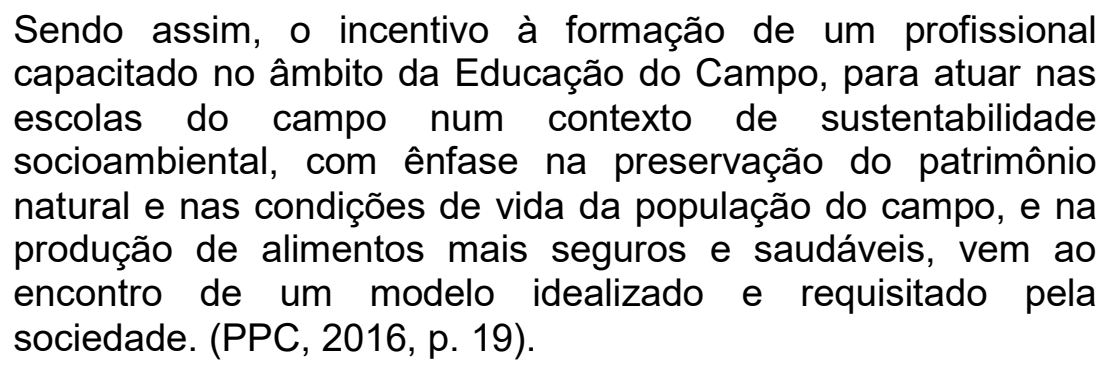

A própria proposta pedagógica do curso, enraizada nestes pressupostos, é pensada por meio de eixos articuladores, a fim de dar conta das diversas dimensões formativas e necessárias ao educador que terá o desafio de modificar este cenário, ou então, atender aquilo que seria este modelo requerido pela sociedade atual.

A gênese da Educação do Campo é resultado da luta dos movimentos sociais organizados, da reivindicação por uma educação básica do campo e no campo, que culminou no I ENERA - Encontro Nacional dos Educadores e Educadoras da Reforma Agrária, realizado no ano de 1997, que se consolidou uma Articulação Nacional no Brasil. Posteriormente foi ampliada e passou a ser uma luta por educação em diferentes níveis de formação para favorecer tanto os povos camponeses, quanto às pautas específicas desses povos, a fim de que consigam reproduzir as condições de sua existência.

Os esforços são na direção de suprir as demandas e atender as necessidades históricas dos povos do campo, situados distantes dos espaços formativos e impedidos, no mais das vezes, pelas particularidades da vida no campo. Ter clareza dessas demandas, situar-se no contexto do campo, perceber o contexto da educação e das escolas do campo, perceber as 
dificuldades enfrentadas, é um passo importante da formação de qualidade dos futuros educadores. Por certo, é também a consciência desta situação das escolas que contribuirá para a melhor preparação e a busca, desde já, por melhores soluções para os problemas apresentados.

Este caráter complexo do desafio da formação humana em

Educação do Campo fundamenta-se, por sua vez, na concepção de que o campo é território de produção de vida, de produção de novas relações sociais, de novas relações entre os homens e a natureza, de novas relações entre o rural e o urbano. A partir daí, faz se necessária uma concepção filosófica e teórica que permita articular o pensar e o fazer pedagógico com a construção de alternativas de desenvolvimento sustentável das comunidades do campo (PPC, 2016, p. 49).

A matriz curricular do curso é atravessada por eixos que compreendem a formação nas dimensões da docência, da pesquisa, da política e da gestão. Ainda, para dar conta da complexidade interdisciplinar, bem como das temáticas comuns e relevantes para a perspectiva da Educação do Campo, cada semestre é orientado por um eixo temático que procura articular as diferentes componentes curriculares e áreas do conhecimento. "Desse modo, entende-se que a organização curricular se apresentará como estratégia que possibilite práticas interdisciplinares investigativas associadas ao tripé ensinopesquisa-extensão" (PPC, 2016, p. 51).

Não menos importante, nesse contexto, é a organização do trabalho pedagógico, pautado, principalmente, pelo desafio do Regime de Alternância, que embora em tempos diferentes (TU e TC), visa-se exatamente a superação da dicotomia entre o pensar e o fazer, ou entre a teoria e a prática. A vivência do cotidiano escolar pelos pibidianos tende a contribuir, especificamente, para os ajustes nesses pontos que alicerçam o curso e o processo formativo.

\section{Concepções de Educação e Formação de Professores}

A aprendizagem do ser professor, da atuação profissional em especial, carrega as marcas da trajetória pessoal e formativa de cada um, trazida a partir das vivências do indivíduo no percurso do processo de escolarização, somadas aos conhecimentos adquiridos quando da formação específica da licenciatura. 
A identidade do ser professor, em especial, da educação do campo ocorre no âmbito teórico, quando da formação acadêmica, mas também atrelada à prática social, às vivências na comunidade na qual se está inserido e às vivências no espaço escolar enquanto prática educacional que está interligada aos saberes pedagógicos (CALDART, 2011).

Os desafios postos pela conjuntura contemporânea exigem um aprimoramento da qualidade do trabalho escolar, por isso faz-se necessário considerar no âmbito de qualquer perspectiva formativa os conteúdos das áreas do saber e ensino, os conteúdos didáticos-pedagógicos, os conteúdos ligados à compreensão humana e social e, ainda, em vista da docência ser um processo de intervenção na prática social, há a necessidade de experiência com vistas a construção de uma consciência crítica sob essa prática profissional.

A atividade pedagógica que ocorre no âmbito da escola não é apenas um processo de ensino - transferência de conhecimentos -, mas também de aprendizagem, um processo que pode ser descrito da seguinte forma:

Saber que ensinar não é transferir conhecimento, mas criar as possibilidades para a sua própria produção ou a sua construção. Quando entro em uma sala de aula devo estar sendo um ser aberto a indagações, à curiosidade, às perguntas dos alunos, as suas inibições; um ser crítico e inquiridor, inquieto em face da tarefa que tenho - a de ensinar e não a de transmitir conhecimento (FREIRE, 2008, p. 47).

Inclusive, questão relevante, é que esse processo pode ocorrer dessa forma, de diálogos horizontais, de relações horizontais, de reciprocidade, mas também pode ocorrer de modo verticalizado, de modo que há uma imposição do conhecimento do ponto de vista do professor e, por vezes, descontextualizado e empobrecido de relações com as vivências da comunidade. Isto é, a formação e preparação do professor ocorre no cotidiano, no processo constante de mediação entre os aspectos teóricos e cognitivos apreendidos no Curso e as questões práticas e concretas do cotidiano escolar.

Nesse caso, sendo possível o contato das Pibidianas e Pibidianos com um ambiente escolar que confirme os aspectos teóricos-pedagógicosmetodológicos poderá reforçar o aprendizado na direção da manutenção e 
elaboração de estratégias aprendidas. O contato com um ambiente diverso, a depender da mediação dos coordenadores e orientadores, poderá resultar num aprendizado diverso, ou então mostrar outras alternativas para a condução das atividades pedagógicas.

[...] A formação profissional para o magistério requer, assim, uma sólida formação teórico-prática. Muitas pessoas acreditam que o desempenho satisfatório do professor na sala de aula depende de vocação natural ou somente da experiência prática, descartando-se a teoria. É verdade que muitos professores manifestam especialmente tendência e gosto pela profissão, assim como se sabe que mais tempo de experiência ajuda no desempenho profissional. Entretanto o domínio das bases teórico-científicas e técnicas, e sua articulação com as exigências concretas do ensino, permitem maior segurança profissional de modo que o docente ganhe base para pensar sua prática e aprimore sempre mais a qualidade do seu trabalho (LIBÂNEO, 1994, p. 28).

Com a introdução dos Pibidianos e das Pibidianas no contexto escolar, parece que há um ganho nesse aspecto da articulação teoria-prática, especialmente, por estarem iniciando a formação teórica e compartilhando do mundo escolar, suas limitações, vicissitudes e condições de existência, podem fazer com que a qualidade da participação no processo formativo seja alterada, vista com mais sentido, ou até se tornem mais participativos, questionadores daquilo que está sendo oferecido como formação. De toda forma, são corriqueiros os comentários dos bolsistas em que apontam, após a inserção na escola, "maior tranquilidade em relação a dar uma aula", "a interagir com os alunos da escola", bem como dos professores formadores de que alguns "bolsistas do PIBID são mais participativos nas aulas", "são mais questionadores".

De outra forma, a interação no espaço escolar, contexto de sua futura atuação profissional, faz com o que os licenciandos/bolsistas percebam as necessidades que se apresentam no cotidiano das escolas do campo, o que possibilita não somente dar sentido para a futura atuação, como também qualificar a formação e preparação para gerir este cenário. O processo formativo do licenciando deve prepará-lo para este universo. De outra forma, 
Numa sociedade organizada, espera-se que a educação, como prática institucionalizada, contribua para a integração dos homens no tríplice universo das práticas que tecem sua existência histórica concreta: no universo do trabalho, âmbito da produção material e das relações econômicas; no universo da sociabilidade, âmbito das relações políticas; e no universo da cultura simbólica, âmbito da consciência pessoal, da subjetividade e das relações intencionais (SEVERINO, 2002, p.11).

Neste posicionamento fica evidente a complexidade do processo de formação de professores, que, enquanto condição de formação escolar precisa ser tocante à humanização dos indivíduos. Se trata de um processo de formação e humanização dos indivíduos, para que eles enquanto professores possam fazer a mediação da própria humanidade, se transformem em forças imprescindíveis para a transformação da existência real, especialmente, numa sociedade classista. Com a inserção dos pibidianos alia-se a formação de professores com a universalização da educação em seus diferentes aspectos, conforme apontou Severino (2002).

A partir da formação acadêmica propriamente dita, concomitante à inserção no ambiente escolar, presume-se que o licenciando tenha condições de perceber algumas questões pertinentes no âmbito das escolas do campo que dizem respeito: a) ao papel do Estado na garantia do direito à educação, nas suas vertentes de políticas públicas que atendem a infraestrutura, alimentação, transporte escolar, dentre outras; b) qualidade da educação, garantias de acesso aos conteúdos e saberes produzidos pela humanidade; c) democratização do acesso aos conhecimentos (à escola!), inclusive questões ligadas à permanência no espaço escolar e ao sucesso na empreitada escolar (inclusão e diversidade escolar); d) a questão profissional propriamente dita, a valorização dos profissionais da educação, financiamento escolar e outras questões.

Outra questão no tocante à formação dos licenciandos da educação do campo, precisa ser o objetivo de superação da atual sociedade burguesa (de classes) e das atuais relações sociais, alienantes, especialmente no sentido de dar-se conta que essa superação não ocorrerá sem o concurso da educação e da promoção da apropriação dos conhecimentos melhor desenvolvidos, pela 
escola. Isto é, se faz importante e necessário que de posse dos conhecimentos, com destaque para a área de formação das Ciências da Natureza, se pensem mecanismos e alternativas para a superação da lógica produtivista do sistema capitalista. Essas alternativas podem ser observadas na condução das atividades pedagógicas por meio da implementação de pomares, agroflorestas, hortas, composteiras nessas escolas parceiras. Isto é, de posse de diferentes conhecimentos se pensam alguns projetos alternativos que visam além do ensino e a aprendizagem, a incorporação da produção de alimentos de forma diversificada, ancorados no eixo da sustentabilidade ambiental. Assim demonstra-se e possibilita-se a discussão de uma outra lógica de produção da vida, diferente da lógica puramente capitalista.

Define-se que a escola tem como papel precípuo a socialização dos conhecimentos melhor elaborados pela humanidade ao longo de sua existência, um processo ativo e mediado pelos professores de transmissãoapropriação desses conhecimentos como forma de humanização dos indivíduos. É uma proposição assentada na tese da socialização dos meios de produção, pois os saberes/conhecimentos são parte integrante e fundamental desses meios de produção. E, somente dessa forma, é possível a definição de um outro papel concomitante da escola: o de superação da sociedade centrada na propriedade privada dos meios de produção, na condição de que a escola não precisa estar condicionada a reproduzir todo sistema de exploração capitalista. Essa é a condição que pode gerar a contradição no sentido de que apesar de a escola ser resultante da constituição da sociedade capitalista, nela podem também se gerar os elementos necessários para a superação dessa sociedade. Afinal de contas, o próprio Marx (1999) alertara que o processo de apropriação de conhecimentos pode ser um processo de alienação:

Não interessava mais saber se este ou aquele teorema era verdadeiro ou não; mas importava saber o que, para o capital, era útil ou prejudicial, conveniente ou inconveniente, o que contrariava ou não a ordenação policial. Os pesquisadores desinteressados foram substituídos por espadachins mercenários, a investigação científica imparcial cedeu seu lugar à consciência deformada e às intenções perversas da apologética (MARX, 1999, p. 24). 
Neste cenário o sentido da ciência pode se tornar problemático, ou seja, a necessidade de que os pressupostos da ciência, do ensino e da aprendizagem escolar, não estejam descolados dos fins humanos, sob o risco da barbárie e da alienação social. Por outro lado, a "popularização da ciência", na perspectiva de oferecer condições de apropriação adequadas aos licenciandos e estudantes, associadas às vivências escolares, pode oferecer elementos para que se pensem alternativas de superação da sociedade capitalista sem que os mesmos se tornem meramente reprodutivistas dos discursos postos pela sociedade e pela ciência.

\section{Processo de Inserção dos Alunos/ Atividades dos Bolsistas no PIBID}

Conforme destacado, a inserção dos estudantes nas escolas se deu após estudos e diálogos acerca do Plano Nacional de Educação (PNE). Tal estudo norteou as discussões posteriores, visto o movimento de implantação da BNCC nas escolas.

Em vista que são três escolas do campo distintas e, cada uma com o seu ou sua respectiva supervisora, os relatos acerca da inserção dos alunos e posterior desenvolvimento das atividades se deram de formas diferentes, mas que visavam atender aos objetivos do PIBID - Educação do Campo.

A vivência inicial com as Escolas do Campo evidenciou as dificuldades encontradas pela comunidade para ter acesso ao ambiente escolar propriamente dito, uma vez que as escolas estão distantes dos centros urbanos de referência. Tais dificuldades levaram os bolsistas ao estudo das políticas públicas do transporte que atendem as essas escolas. Encontraram vários trabalhos, inclusive de colegas do Curso que já haviam sinalizado que se tem uma política direcionada ao transporte (Programa Nacional de Transporte Escolar - PNATE), porém a mesma é precarizada, uma vez que depende de um complexo de questões, a exemplo das condições climáticas, precariedade de estradas e dimensões geográficas (VIEIRA, 2018).

Para os bolsistas irem para a escola, no Anna Riet Pinto, passava, necessariamente, pela disponibilidade de caronas dos colegas que possuíam algum meio de transporte particular, assim como os professores da referida 
escola. O deslocamento dos estudantes era feito por meio de transporte público que percorria as estradas rurais até as comunidades, casas, trazendoos para a escola e, na saída, a rotina inversa.

Para a ida na escola Risoleta Quadros os estudantes puderam fazer uso do transporte público, tendo, contudo, que se deslocarem a partir das $5 \mathrm{~h}$ da manhã, fazendo o trajeto de busca dos estudantes, para estar na escola no horário de início das atividades escolares propriamente ditas (8h da manhã).

Para o acesso a escola Antônio Conselheiro os estudantes/bolsistas utilizavam os transporte escolar, sendo que eles precisaram se organizar em grupos, pois nem sempre havia ônibus com vagas para os mesmos. A escola fica em torno de $35 \mathrm{~km}$ do meio urbano, e esse trajeto em dias de chuva se transformava num rali e, em dias secos, num "banho" de poeira.

Porquê se destaca inicialmente o acesso às escolas? Porque se entende que ao passo que os estudantes/bolsistas se tornam conhecedores da realidade de acesso à escola, os mesmos passam a fazer parte daquele espaço e tempo, não como algo pontual e sim como parte da formação. Conseguem entender as primeiras motivações e esforços dos estudantes para estarem na escola.

Outras demandas vieram na sequência. Na Escola Anna Riet Pinto, iniciou-se um trabalho de sensibilização dos estudantes para com o lixo. Neste sentido a estratégia desenvolvida foi a utilização, num primeiro momento, de discussões a partir de um filme. A partir das reflexões o grupo planejou e apresentou uma peça de teatro, para contribuir na compreensão da importância do tratamento do lixo. Novas discussões foram feitas com a introdução de conceitos das Ciências da Natureza e, como resultado, foram colocadas lixeiras para separação dos resíduos. Ainda, pensando em ações/questões ambientais, foi realizado um estudo para revitalização do pátio da escola. $O$ supervisor sugeriu que fossem plantadas árvores frutiferas, as quais no futuro viessem a contribuir inclusive na merenda escolar. Neste sentido, mobilizou-se os estudantes para, junto aos bolsistas, plantarem as árvores, as quais foram adquiridas com recurso CAPES. 
Para auxiliar os professores da escola na aprendizagem de alguns conhecimentos na área de ciências, foi solicitado aos pibidianos e pibidianas que estudassem e aplicassem atividades experimentais. Especialmente, por que se entende que a experimentação no Ensino de Ciências, defendida por diversos autores, é considerada importante recurso pedagógico, pois propicia o entendimento dos conceitos, ilustrando os princípios teóricos, assim como testagem de hipóteses a partir de coleta de dados, a exemplo da realização de atividades investigativas simples, passível de realizá-las em pequenos grupos, aumentando gradualmente o nível de complexidade dos problemas, conforme a familiarização dos estudantes (ROSITO, 2003).

$\mathrm{Na}$ escola Risoleta Quadros, a partir da sua realidade, foram desenvolvidas estratégias que atendessem as demandas apresentadas pela mesma. Iniciou-se com um cine pipoca com a intenção de sensibilizar os estudantes para as questões de valorização e pertencimento ao lugar onde estão. Na sequência, foi desenvolvido um projeto coletivo, com a comunidade, para a revitalização da horta escolar. Na Risoleta Quadros, em momentos anteriores, outros projetos já haviam sido desenvolvidos e já se tinha uma estrutura para a horta, inclusive com estruturas de estufas. O projeto anterior teve a participação da EMATER-Ascar-RS. Contudo, com a chegada dos pibidianos e pibidianas a escola e a comunidade pediram que essa fosse revitalizada. Com recursos da CAPES foram adquiridos mudas, adubo e ferramentas para auxiliar na (re)construção. Houveram muitos estudos para que a horta tivesse intencionalidade pedagógica, sendo inclusive inserida no Projeto Pedagógico da Escola.

Da mesma forma os bolsistas auxiliaram os professores na aprendizagem dos conceitos de ciências, realizando também atividades experimentais. Pode-se destacar que as atividades propostas se utilizaram de materiais alternativos e de baixo custo. Pois, concordamos com Rosito (2003) que é possível desenvolver atividades experimentais na sala de aula e até fora dela, fazendo uso desses materiais, sendo que isso auxilia significativamente no desenvolvimento da criatividade dos alunos. Ao afirmar, o autor, não quer dizer que não considere a importância de um laboratório bem equipado para 
garantir um bom ensino, apenas acredita que é necessário ultrapassar as ideias de que se necessita de um espaço específico e equipado para o desenvolvimento de um ensino fundamentado nos livros didáticos. Neste sentido também corroboramos com Vieira e colaboradores (2007) que destacam a importância de atividades experimentais, em sala de aula, de baixo custo. Especificamente quando têm baixo custo operacional e tendem a gerar pouco ou nenhum resíduo, além de possibilitar que mais experiências sejam desenvolvidas ao longo do ano letivo.

Na Escola Antônio Conselheiro houve, inicialmente, uma reunião de integração entre a Supervisora do PIBID, as(os) bolsistas do PIBID, a orientadora da Universidade e demais professores que constituem a escola, a fim de que todos reconhecessem o PIBID como parte do contexto escolar. A partir do diálogo de integração alguns professores destacaram demandas que entendiam ser urgentes, a exemplo de uma agrofloresta iniciada e não finalizada, a horta da escola que carecia de revitalização e o descarte correto dos alimentos consumidos na escola.

As demandas foram anotadas para posterior estudo, pois a supervisora e orientadora intencionavam que as(os) bolsistas percebessem o papel pedagógico do trabalho que seria desenvolvido. Para tanto, se organizou as(os) bolsistas em grupos em que cada um ficou responsável pelo estudo de uma demanda elencada junto a escola.

O estudo foi orientado a partir da retomada do PNE e de artigos da área de Ensino de Ciências, em que foram construídos projetos pedagógicos. Tais projetos tinham como fundamentação a abordagem por temas (DELIZOICOV; ANGOTTI; PERNAMBUCO, 2018). Ou seja, a demanda identificada junto a escola foi estudada como um tema, sendo que este precisava ser justificado para posterior definição dos conceitos, necessários para compreensão e aprofundamento do tema. A justificativa se faz necessária para que a intencionalidade pedagógica não recaia numa perspectiva tecnicista, mas dialógica (SILVA, 2007).

Nesse sentido, foram elaborados três projetos pedagógicos (Agrofloresta em uma Escola do Campo; Horta Escolar Convencional e Introdução as 
Plantas Alimentícias não Convencionais - PANC; Minhocário e Composteira como Recursos Pedagógicos em uma Escola do Campo). Os projetos foram importantes ao passo que as(os) bolsistas foram percebendo que não bastava chegar na escola e desenvolver atividades práticas, pois o trabalho seria desenvolvido com estudantes da escola, professores e funcionárias, ou seja, precisava ter clareza da intencionalidade pedagógica.

A partir dos projetos pedagógicos elaborados se iniciou 0 desenvolvimento dos mesmos. Cabe destacar que a construção dos projetos ocorria num espaço em que a escola destinou ao PIBID (salinha do PIBID, com mesa, estante e quadro) e na Unipampa, Campus de Sant'Ana do Livramento. Os projetos foram desenvolvidos com estudantes do Ensino Fundamental da escola com apoio de alguns professores, e também com as funcionárias que trabalham na cozinha.

O trabalho com estudantes do Ensino Fundamental envolveu o estudo sobre o que é uma agrofloresta e a importância da mesma para o ecossistema, sendo acompanhado por dois professores da área de agroecologia. A partir do estudo, se deu início a revitalização da agrofloresta. Ressaltamos que esse processo de revitalização envolveu também um morador da comunidade, pois ele possui um sistema agroflorestal em sua propriedade e compartilhou seus saberes acerca do assunto.

A horta escolar envolveu o estudo do relógio do corpo humano, o qual,

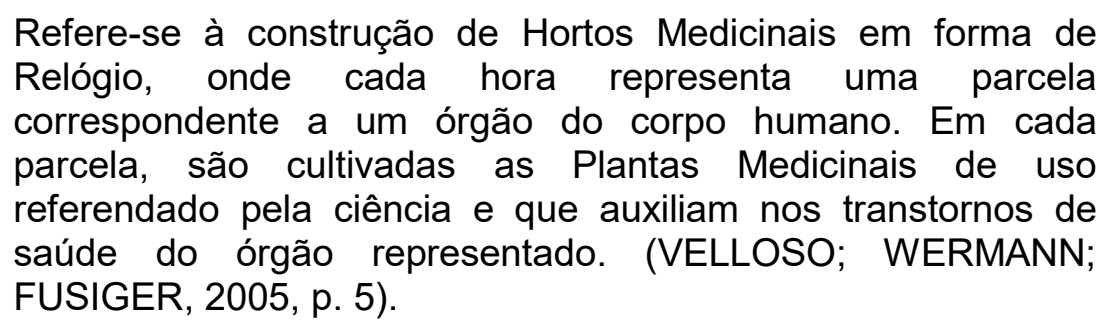

Optou-se por esse modelo de horta em função dos estudantes da escola terem certo conhecimento, mas que carecia de aprofundamento e prática. 0 trabalho com as PANC foi iniciado, mas não foi concluído e, assim que for possível, será retomado.

O trabalho com as funcionárias da escola envolveu atividades com jogos pedagógicos a partir do estudo sobre as minhocas. Tais atividades 
compreendem o projeto sobre o minhocário e composteira, pois conforme relatos dos professores da escola o descarte incorreto dos alimentos (mesmo que dentro de uma composteira) levava a produção de um solo improdutivo e a morte das minhocas. Desse modo, o jogo envolvia o conhecimento sobre os tipos de minhocas e a importância delas para o solo. O que culminou na construção de um minhocário e uma composteira (PRESTES, et al, 2019).

Além das atividades e estudos realizados nas escolas, os acadêmicos e acadêmicas bolsistas participaram da organização de eventos, tiveram 0 protagonismo em projetos de extensão da Unipampa, como a I e II Mostra de Extensão Universitária, que visa a divulgação de ações extensionistas da Universidade. O evento é anual e, no primeiro ano, 2018, os bolsistas desenvolveram oficinas de leituras aos visitantes, junto a programação da Biblioteca do Campus, além da divulgação do programa e das ações realizadas nas comunidades escolares. No segundo ano, 2019, os bolsistas se envolveram em outras ações para além daquelas realizadas no ano anterior, foi apresentada uma peça de Teatro, uma adaptação da peça apresentada na Escola Anna Riet sobre o tratamento do lixo. Outro evento com a participação dos bolsistas é no Anima Campus, que também é realizado anualmente no Campus da Universidade, que tem objetivo "abrir" o Campus para a comunidade, realizando ações de divulgação e divertimento. Neste sentido, no primeiro ano, 2018, os acadêmicos trouxeram para divulgação as pesquisas que haviam realizado sobre o uso de plantas medicinais. No segundo ano, se articularam com outros programas e promoveram cine pipoca, com filmes diversos, para diferentes públicos. Também fizeram a adaptação de um teatro de fantoches sobre conhecimentos do sangue.

Outro evento que significou bastante aos acadêmicos foi a participação deles no evento Institucional do PIBID, o INTRAPIBID, que se realizou em Bagé-RS no ano de 2019. Neste encontro os bolsistas puderam dialogar entre os diferentes subprojetos, conhecer realidades e estratégias diferentes para a prática docente. Em seus relatos posteriores, todos sinalizaram da importância desses eventos, em que os bolsistas eram os protagonistas, do diálogo, e das possibilidades de aprendizagem. 
Ao longo dos dezoito meses de atividades os pibidianos e pibidianas foram incentivados a participar de diferentes eventos, como semana acadêmica, com rodas de conversa, no Salão Internacional de Ensino Pesquisa e Extensão (SIEPE) da Unipampa, com mostra/divulgação de trabalhos. Foram proporcionados também, durante o Tempo Comunidade do Curso, atividades com diferentes atores da comunidade interna e externa da Universidade, com intuito de conhecer mais sobre os saberes docentes, as políticas públicas entre outros.

Para o encerramento das atividades foi proposto um seminário, no qual pode-se escutar a todos e todas sobre as suas vivências e aprendizagens. Consideramos um espaço significativo para as sistematizações, as construções coletivas e individuais dos bolsistas, o relato e avaliação dos supervisores das escolas, dos ganhos e das fragilidades que encontraram no desenvolvimento do projeto.

\section{Considerações Finais}

O PIBID, enquanto um programa, política pública de incentivo e qualificação da formação inicial de professores, tem por objetivo principal aproximar os licenciandos da realidade escolar, numa ponte entre o ensino superior e a educação básica. Esse objetivo mais amplo espera-se ser alcançado por meio de ações didáticos-pedagógicas.

No PIBID do subprojeto da LeCampo esse objetivo geral foi alcançado quando por meio das vivência no ambiente escolar os estudantes conseguiram aprofundar estudos na área de Educação do Campo - Ciências da Natureza, desenvolver processos de escrita, organizar atividades pedagógicas e preparar aulas, fazer algumas intervenções no cotidiano escolar, especialmente, nas atividades de ensino com a perspectiva lúdica e por meio jogos, além das atividades experimentais de baixo custo, utilizando de materiais alternativos.

Ao longo do desenvolvimento do projeto, os pibidianos e pibidianas conheceram a realidade escolar das escolas do campo e principalmente identificaram alguns dos desafios da docência na Educação do Campo. Desafios que, inclusive, estão para além da sala de aula, do conteúdo, pois 
precisa-se saber sobre gestão, políticas públicas, para que sejam assegurados os direitos à educação. Não menos importante, cuidado e acolhimento das pessoas que estão/são a comunidade escolar.

A inserção no contexto escolar proporcionou uma diversidade de vivências, muitas aprendizagens que com certeza irão contribuir nas ações desses futuros docentes, bem como uma revitalização das ações dos supervisores, que ensinaram e aprenderam coletivamente.

Em síntese, os tempos e espaços que constituem a formação em Educação do Campo associado às experiências possibilitadas pelo PIBID nos levam a emergência de processos de formação permanente coletiva, em que os professores da universidade, das escolas, estudantes da licenciatura e comunidade escolar se envolvam no compromisso de uma Educação do Campo comprometida com as escolas e com os povos do campo.

\section{Agradecimentos}

À CAPES pelas Bolsas concedidas e ao Apoio Financeiro que viabilizou o PIBID, bem como à UNIPAMPA por todo o aporte de logística e institucionalização do Projeto.

\section{Referências}

BRASIL. Coordenação de Aperfeiçoamento de Pessoal de Nível Superior. CAPES. PIBID - Programa Institucional de Bolsa de Iniciação à Docência. Disponível em <https://www.gov.br/capeseducacao-basica/capespibid/editais-eselecoes>. Acesso em 22 de ago. de 2020.

CERQUEIRA, M. C. A ; SANTOS, C. R. B. As Escolas Famílias Agrícolas, A Pedagogia da Alternância e o Caderno da Realidade. In: I Seminário Regional e I Fórum de Educação do Campo da Região Sul do RS: Campo e Cidade em busca de Caminhos Comuns, 2012, Santa Maria, RS. Anais. SIFEDOC Regional, Santa Maria: UFSM, 2012. p. 1 - 15. Disponível em: http://coral.ufsm.br/sifedocregional/images/Anais/Eixo\%2004/Marcia\%20Cristin a\%20de\%20A.\%20Cerqueira \%20e\%20C\%C3\%A9lia\%20Regina\%20B.\%20dos $\% 20$ Santos.pdf. Acesso em: 05 set. 2020.

CHELOTTI, M.C.; PESSOA, V. L. S. A luta pela terra na microrregião geográfica da Campanha Central/RS/BR: os sem-terra chegaram no "coração" do latifúndio gaúcho. In: Simpósio Internacional de Geografia Agrária, 2007, Londrina. Anais. Londrina: UEL, 2007, p. 73-89. 
DELIZOICOV, D.; ANGOTTI, J. A.; PERNAMBUCO, M. M. Ensino de Ciências - fundamentos e métodos. 5. ed. São Paulo: Cortez, 2018.

FREIRE, Paulo. Pedagogia do Oprimido. São Paulo: Paz e Terra, 2008.

GATTI, B. A.; ANDRE, M. E. D. A. A Relevância dos Métodos de Pesquisa Qualitativa em Educação no Brasil. In: WELLER, W.; PFAFF, N. (Org.). Metodologias da pesquisa qualitativa em Educação: Teoria e Prática. Petrópolis: VOZES, 2010.

LIBÂNEO, José Carlos. Didática. São Paulo: Cortez, 1994.

MARX, Karl. O capital: crítica da economia política. São Paulo: Civilização Brasileira, 1999.

PRESTES, G.; KLEMS, J.; MENDILARZO, G. MACHADO, A.R. Minhocário E Composteira Como Recursos Pedagógicos Em Uma Escola Do Campo A Partir Do Pibid-Lecampo. In. $11^{\circ}$ Salão Internacional de Ensino, Pesquisa e Extensão, Anais, Bagé: Unipampa, 2019.

ROSITO, B. A. O ensino de ciências e a experimentação. In: MORAES, R. Construtivismo e ensino de ciências: reflexões epistemológicas. 2. ed. Porto Alegre: EDPUCRS, 2003, p. 195 - 208.

SANTOS, A. L. M. dos.; DAVID, C. D. O Espaço Rural na Região da Campanha Gaúcha: Territorialidades e Desenvolvimento. $O$ caso do assentamento Conquista do Caibaaté, São Gabriel- RS. In. Revista do Departamento de Geografia - USP, São Paulo, v. 22, p. 57 - 81, novembro de 2011.

SEVERINO, A. J. Competência técnica e sensibilidade ético-política: o desafio da formação de professores. Cadernos FEDEP (Fórum Estadual de Defesa da Escola Pública), São Paulo, n.1, p.10-23, fevereiro de 2002.

SILVA, A. F.G (Org.). A busca do tema gerador na práxis da educação popular. Curitiba: Editora Gráfica Popular, 2007.

VIEIRA, H. J.; FIGUEIREDO-FILHO, L. C. S., e FATIBELLO-FILHO, O.: "Um Experimento Simples e de Baixo Custo para Compreender a Osmose". Química Nova na Escola, n. ${ }^{\circ} 26, \mathrm{p} .37-39$, nov. 2007. Disponível em < http://qnesc.sbq.org.br/online/qnesc26/v26a11.pdf> Acesso em 17 de set. de 2019

VELLOSO, C. C.; WERMANN, A. M.; Fusiger, T.B. Horto Medicinal - relógio do corpo humano. Emater-RS, 2005. Disponível em: http://atividaderural.com.br/artigos/4fc504ba9a5b5.pdf. Acesso em 05 ago. 2020.

VIEIRA, R.M.R. As políticas públicas e o Transporte Escolar: a realidade das escolas no campo de Dom Pedrito-RS. 2018. 43f. Trabalho de Conclusão 
de Curso (Licenciatura em Educação do Campo) Universidade Federal do Pampa, Rio Grande do Sul, Dom Pedrito, 2018.

\section{Sobre os autores}

\section{Denise da Silva}

deniseds@unipama.edu.br

Licenciada em Química pela Universidade Federal de Santa Maria (UFSM), mestre em Educação em Ciências (UFSM), doutora em Educação em Ciências pela Universidade Federal do Rio Grande do Sul (UFRGS), é professora adjunta da Universidade Federal do Pampa- UNIPAMPA, participa do Grupo de Estudo e Pesquisa em Educação do Campo, coordenadora de área do Programa Institucional de Bolsas de Iniciação à Docência (PIBID) subprojeto Educação do Campo - UNIPAMPA. Dom Pedritro, RS - BR.

\section{Aniara Ribeiro Machado}

aniaramachado@unipampa.edu.br

Doutora em Educação Científica e Tecnológica pela Universidade Federal de Santa Catarina. Tem como como formação inicial Licenciatura em Física e habilitação em Matemática pela Universidade Regional do Noroeste do Estado do Rio Grande do Sul. Lecionou Física em escolas públicas e privadas no Rio Grande do Sul e Santa Catarina, o que possibilitou conhecer e problematizar a realidade da formação de professores (inicial e continuada). No ano de 2015 ingressou como professora substituta no curso de Pedagogia na Universidade Federal do Pampa (UNIPAMPA-Jaguarão) e em 2016 como professora efetiva no curso Educação do Campo - Ciências da Natureza pela UNIPAMPA de Dom Pedrito-RS. Membro do Grupo Colaborativo de Estudo e Pesquisa: FLEXILHAS e CoEducar: Aprender em ação, Metodologias de Ensino e Formação de Professores. Tem atuado em projetos de ensino, pesquisa e extensão voltados à formação de professores na área das Ciências da Natureza e Educação do Campo.

\section{Algacir José Rigon}

algacirrigon@unipampa.edu.br

Licenciado em Filosofia e Mestre em Educação pela Universidade de Passo Fundo (UPF); Doutor em Educação pela Universidade de São Paulo (FE-USP). Trabalhou como Professor na Universidade Braz Cubas - UBC e na UMC Universidade de Mogi das Cruzes. Desde 2014 trabalha na Universidade Federal do Pampa - UNIPAMPA. Participa do Grupo de Estudo e Pesquisa da Atividade Pedagógica (GEPAPe) e do Grupo de Estudo e Pesquisa em Educação do Campo. As atividades executadas envolvem o Ensino, a Pesquisa e a Extensão. 